\title{
Using GIS to evaluate sewage network at AI- Khoud district, Al-Seeb, Sultanate of Oman
}

\author{
L.K. AZAZ* \\ M. Al Suleimani
}

\begin{abstract}
Sewage system plays a vital role in the economic development of any country in the World. In this paper; GIS have been utilized to evaluate sewage network at AlKhoud district, Al-Seeb, Sultanate of Oman. This district has been selected for this study because of its high importance not only in Al-Seeb Welayat, but also in Oman in general. This study proofed the importance of utilizing GIS in sewage networks analysis. Spatial Analysis has been applied in this study for defining the area which is served by the sewage network and the area which is not served by sewage network, and calculating percentage of each area. GIS has been used to calculate the capacity of the existing sewage network and the Sewage treatment plants in the study area. Spatial Analysis has been applied to define the impacts of Gono tropical Cyclone on the sewage network in the study area. GIS has been used to evaluate the suitability of the current location of the Sewage Treatment Plant (STP). GIS has been used to Search for the best location for Sewage Treatment Plant (STP) in the study area. Finally, GIS has been used for defining the best size for future Sewage Treatment Plant (STP). [Bul. Soc. Géog. d'Égypte, 2017, 90: 201-216]
\end{abstract}

Key Words: GIS - Sewage network - Al-Khoud district -Spatial Analysis- Sewage Treatment Plant (STP)

\section{Area of Study}

Al-Khoud district is located in Al-Seeb Welayat. Al-Seeb Welayat is the largest Welayat in Muscat, the capital of Oman. Al-Khoud district is srounded by Al-Mabila (north), Al-Mawaleh (south), Al-Hail (east) and AlKhoud village (west), (Figure 1). Al-Khoud district is considered as one of the most important areas in Al-Seeb Welayat. Sultan Qaboos University, is the only governmental University in Oman, is very close to Al-Khoud district. Wadi Samail which is one of the biggest valleys in Sultanate of Oman is located nearby as well. This district has been selected for this study because of its high importance not only in Al-Seeb Welayat, but also in Oman in general. As a result of its importance, the district has been witnessed impressive urban expansion, Figure (2) shows the detailed map of the area of study.

* Associate Professor, Menofya University and Qassim University. 


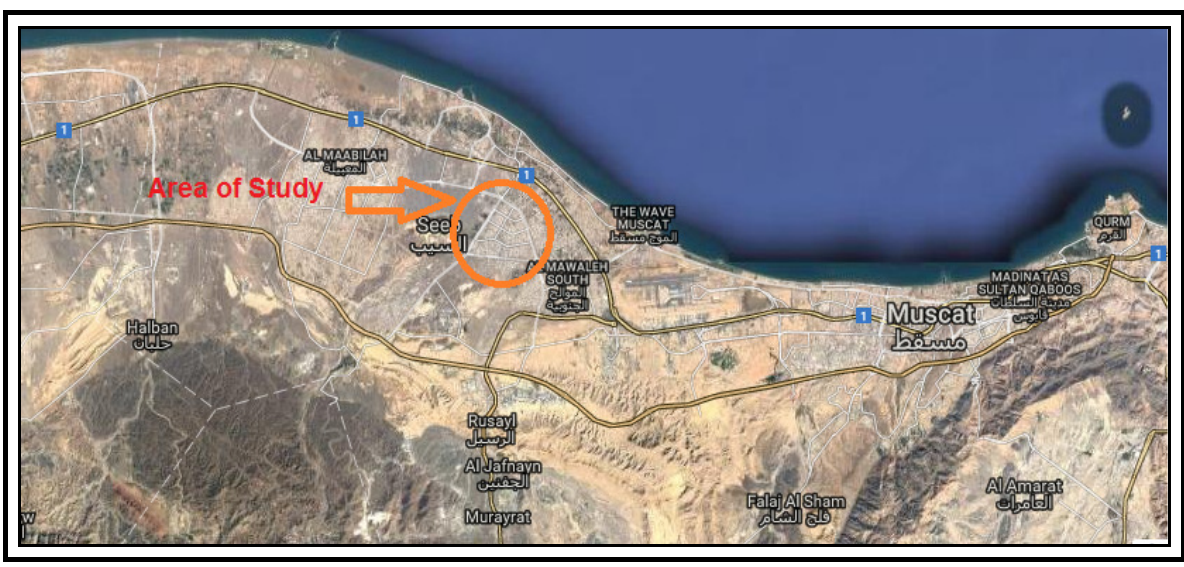

Figure 1. The location of the study Area, Image from Google Map, (2017).

\section{Objectives:}

This study has the following main objectives:

1- Defining the area which is served by the sewage network and the area which is not served by sewage network, and calculating percentage of each area.

2- Calculating the capacity of the existing sewage network and the Sewage treatment plants in the study area.

3- Highlighting the Problems of sewage network in the study area including the impacts of Gono tropical Cyclone on the sewage network in the study area.

4- Evaluating the suitability of the current location of the Sewage Treatment Plant (STP).

5- Searching for the best location of Sewage Treatment Plant (STP) in the study area.

6- Defining the best size for future Sewage Treatment Plant (STP).

\section{Data and Methodlogy}

\section{1) Data Collection:}

The data have been collected from many sources:

- Sewage network data have been collected from Haya Water Company as vector data including the following:

- Manhole data and its attributes as points.

- $\quad$ Piping data and its attributes as lines.

- $\quad$ Sewage Treatment Plant (STP) data and its attributes as points.

- Plots data as polygon and Road data as lines have been collected from the Ministry of Housing. 
- Population data as Excel files have been collected from the Ministry of National Economy.

- Gonu Imagery, Ikonos satellite image, date: June 12, 2007, as a raster layer have been collected from the Supreme Committee for Town Planning

- Digital Elevation Model data (DEM) 30-meter resolution, as raster layer have been collected from the Supreme Committee for Town Planning. GIS section has produced it in house.

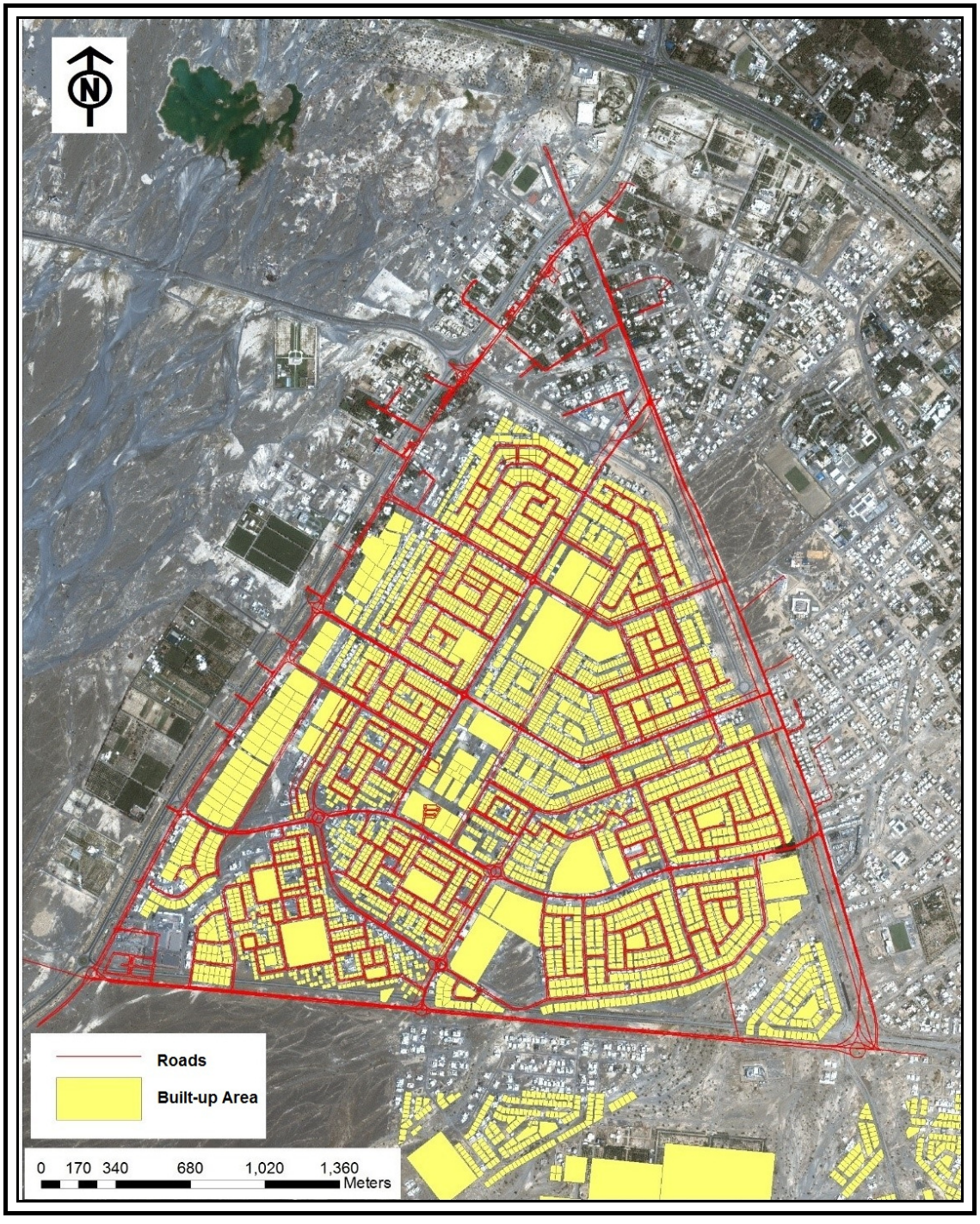

Figure 2. The area of Study, Produced by Authors. 
2) Data Entry:

- ArcGIS 9.2 for raster and vector data entry.

3) Spatial and Statistical Analysis:

- $\quad$ Structure query language (SQL) has been used to define the area served by sewage network by selecting plots that contain manholes.

- Volume Formula has been used to Calculate the capacity of sewage network in the study area using the attributes tables of the pipes layer.

- Classification of pipes per diameter has been done using "Symbology" tab inside "Layer Properties" Window.

- Calculation of the wetlands areas and the areas which covered by mud (to measure the impacts of Gono tropical Cyclone on the sewage network in the study area) have been done using " Calculate Geometry" function. ArcGIS uses planimetric algorithms to calculate geometry such as area and perimeter.

- A single-objective multi-criteria analysis has been implemented in Searching for the best location of Sewage Treatment Plant (STP) in the study area

- Projection of future number of population formula and the Oman Urban Planning Guide standards have been used to define the best size for future Sewage Treatment Plant (STP) according to the forecasted figures of population

\section{Results}

Before discussing the results of the spatial analysis in this study, it is imperative to shed some light on the elements of sewage network (Figure 3).

The wastewater of the houses goes to service laterals. Service laterals are connecting to Local main sewer line. The Local main sewer line is linked to the manholes. The manholes flow to the regional trunk line sewer which assembled at the end in the Sewage Treatment Plant.

\section{1) Defining the areas which are served by sewage network}

In Arc Map, the sewage network layers and plots layer have been loaded and overlapped. Structure query language (SQL) has been used to define the area served by sewage network by selecting plots that contain manholes. If the plots contain manholes, this means it is served by sewage network. Figure (4) illustrates the Served Area by the sewage network (Red color) and Not Served Area (Yellow color). 
The total area served by sewage network is $406653.9136 \mathrm{~m}^{2}$ which represent only $5.8 \%$ of the total study area. Indeed, this means that $94.2 \%$ is not served by the sewage network. In terms of residential plots, the total number of plots is 3947, only 901 plots are served by the sewage network. This means that $22.8 \%$ of plots is served by the sewage network, while $77.2 \%$ of plots is not served by the sewage network. The smallest residential area is $383.3 \mathrm{~m}^{2}$, while the largest residential area is $15203.3 \mathrm{~m}^{2}$. The mean of the residential area is $403.8 \mathrm{~m}^{2}$.

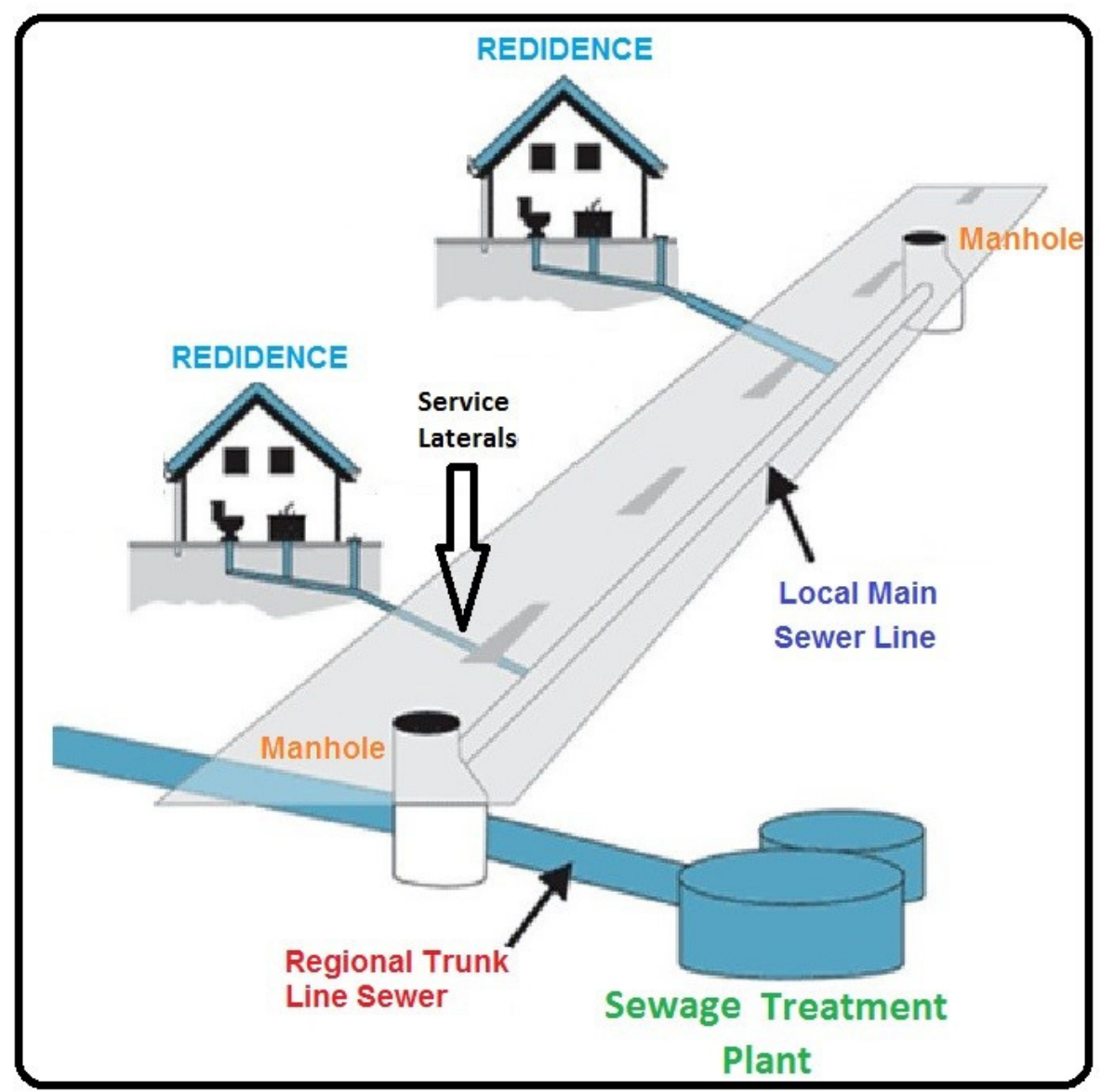

Figure 3. The elements of sewage network.

Source: Civil Engineers PK. 


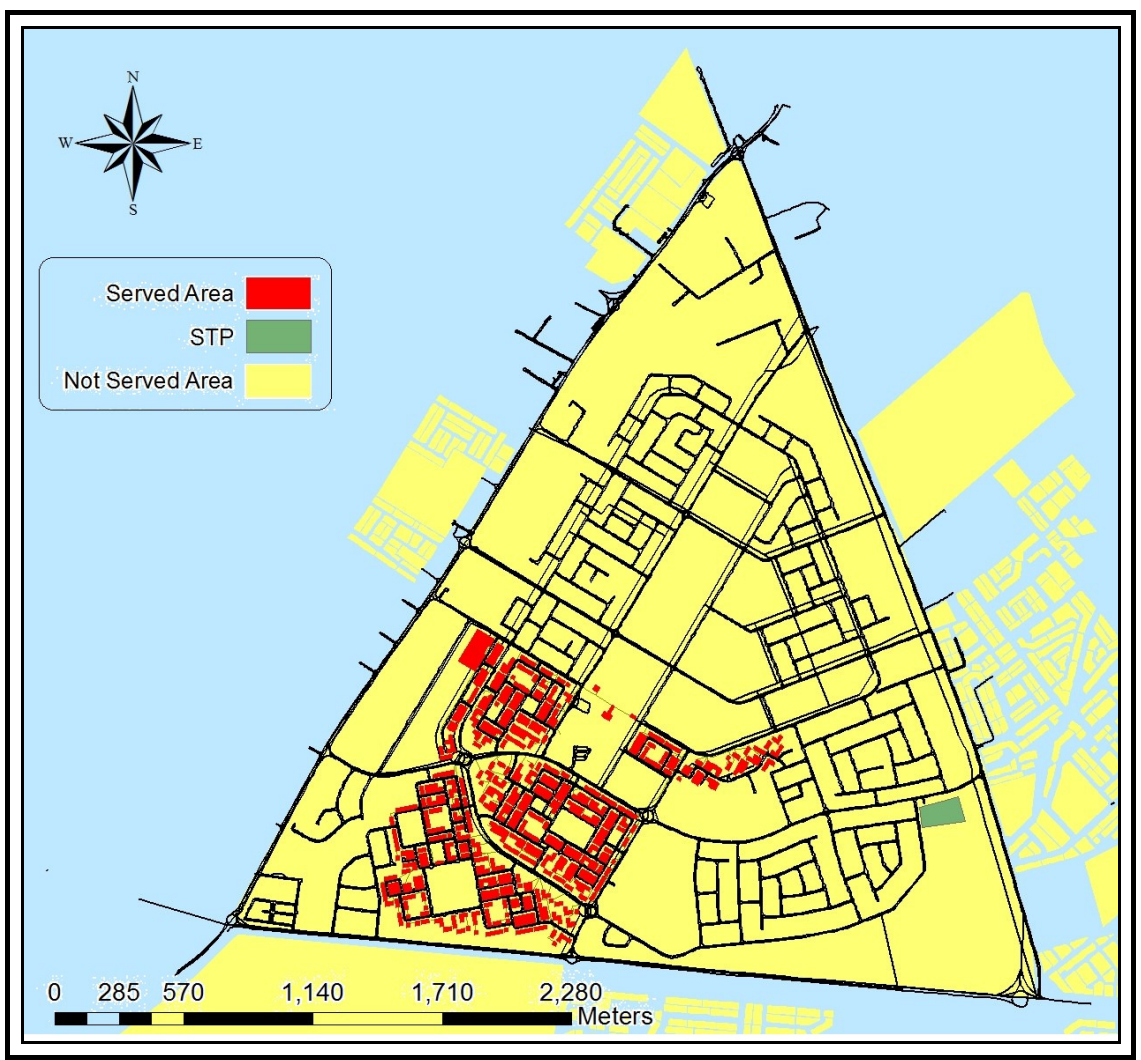

Figure 4. Served Area by sewage network and Not Served in Al-Khoud, Produced by Authors.

\section{2) Calculating the capacity of sewage network in the study area}

The following formula have been used to calculate the capacity of the sewage network:

$$
\text { The Volume }=\left(\frac{\pi}{4}\right) \times D^{2} \times \text { Length }
$$

Where the volume $=$ capacity

\section{$\pi=3.14$ \\ D = Diameter \\ Length $=$ length of the pipes}

The attributes tables of the pipes layer have two columns which is important for calculating the capacity of sewage network these columns are: 
- Diameters (from $100 \mathrm{~mm}$ to $-150 \mathrm{~mm}-200 \mathrm{~mm}-250 \mathrm{~mm}-300 \mathrm{~mm}-350$ $\mathrm{mm}$ and $400 \mathrm{~mm}$ ).

- $\quad$ Length (from $2.3 \mathrm{~m}$ to $34884 \mathrm{~m}$ ).

Table (1) shows the number of pipes and its diameters and lengths. Finally, the capacity of sewage network has been calculated using the abovementioned formula, Table (2). Figure (5) shows the classification of pipes per diameter.

Table 1. The number of pipes and its diameters and lengths, Produced by Authors.

\begin{tabular}{|l|c|c|c|}
\hline & Number of Pipes & Diameter $(\mathbf{m m})$ & Length $(\mathbf{m})$ \\
\hline & 916 & 100 & 17954.24833 \\
\hline & 450 & 150 & 11656.15408 \\
\hline & 41 & 200 & 2269.127646 \\
\hline & 36 & 250 & 2508.897779 \\
\hline & 4 & 300 & 252.299762 \\
\hline & 1 & 350 & 21.373812 \\
\hline Total & 4 & 400 & 222.62407 \\
\hline
\end{tabular}

Table 2. The capacity of sewage network in the study area, Produced by Authors.

\begin{tabular}{|c|c|c|c|c|}
\hline & $\begin{array}{c}\text { Number of } \\
\text { Pipes }\end{array}$ & $\begin{array}{c}\text { Diameter } \\
\text { (mm) }\end{array}$ & $\begin{array}{c}\text { Capacity } \\
\left(\text { meter }^{3}\right)\end{array}$ & $\begin{array}{c}\text { Capacity } \\
\text { (liter) }\end{array}$ \\
\hline & 916 & 100 & 140.8984675 & 140898.4675 \\
\hline & 450 & 150 & 203.3803982 & 203380.3982 \\
\hline & 41 & 200 & 72.53532888 & 72535.32888 \\
\hline & 36 & 250 & 123.0927973 & 123092.7973 \\
\hline & 4 & 300 & 17.8249782 & 17824.9782 \\
\hline & 1 & 350 & 2.055359196 & 2055.359196 \\
\hline & 4 & 400 & 27.96158323 & 27961.58323 \\
\hline Total & 1452 & & 587.7489125 & 587748.9125 \\
\hline
\end{tabular}

\section{3) The Problems of sewage network in the study area}

This sewage network has some problems due to the absence of good planning for this network. The problems can be defined in the following points:

1. The sewage network pipes pass through the buildings (Figure 6). It should be outside the buildings according to the planning standards, therefore, if one of these pipes blocked, it will lead to stop the flowing of wastewater to the main line and hence the other buildings will suffer from the same problem. 


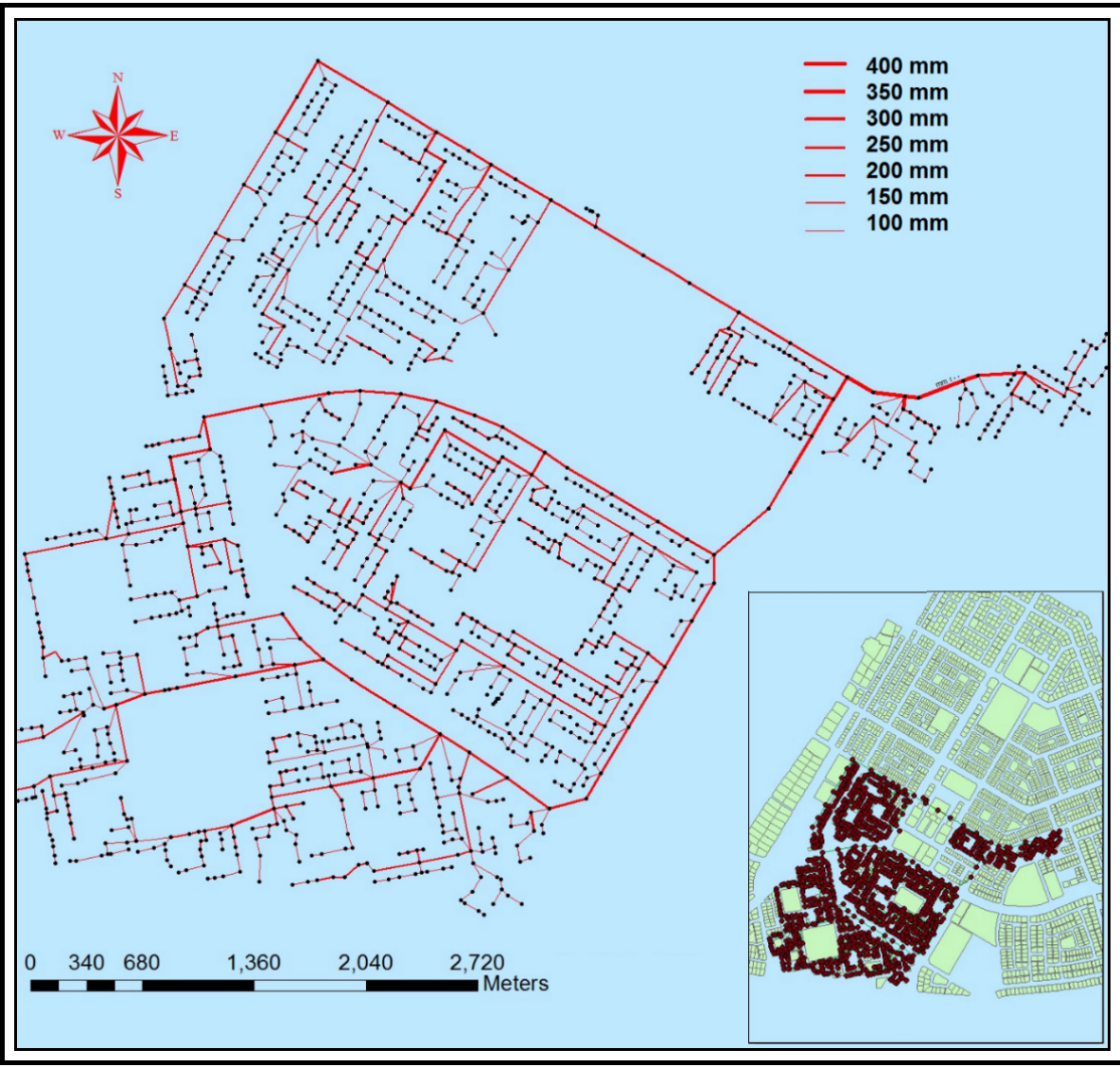

Figure 5. Classification of pipes per diameter, Produced by Authors.

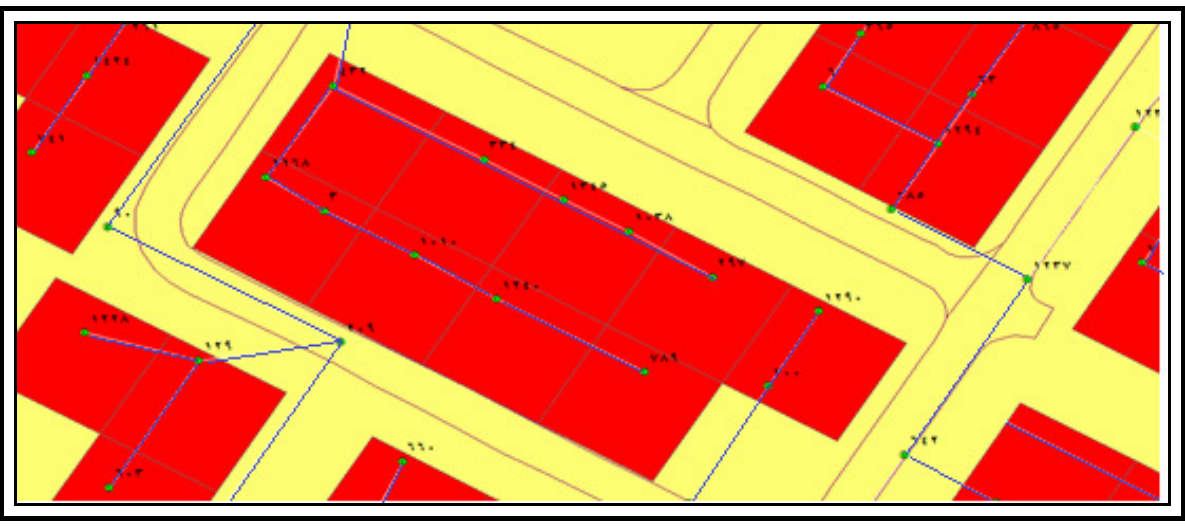

Figure 6. The pipelines that pass-through buildings (blue lines), Produced by Authors. 
2. The sewage network suffered from major problems during Gonu tropical cyclone. It was a Super Cyclonic Storm. Cyclone Gonu was the strongest tropical cyclone on record in the Arabian Sea, and tied for the strongest tropical cyclone on record in the northern Indian Ocean and was the strongest named cyclone in this basin. On June 5,2007, it made landfall on the eastern-most tip of Oman with winds of $150 \mathrm{~km} / \mathrm{h}(90$ $\mathrm{mph}$ ). Gonu dropped heavy rainfall near the eastern coastline, reaching up to $610 \mathrm{~mm}$ (24 in.), which caused flooding and heavy damage. The cyclone caused about US \$4 billion in damage and nearly 50 deaths in Oman, where the cyclone was considered the nation's worst natural disaster (Azaz, 2009). There were two elements (Mud, wet lands) can be monitored as consequences of Gonu tropical cyclone. Figures (7) and (8) show these two elements in the study area including the area served by sewage network.

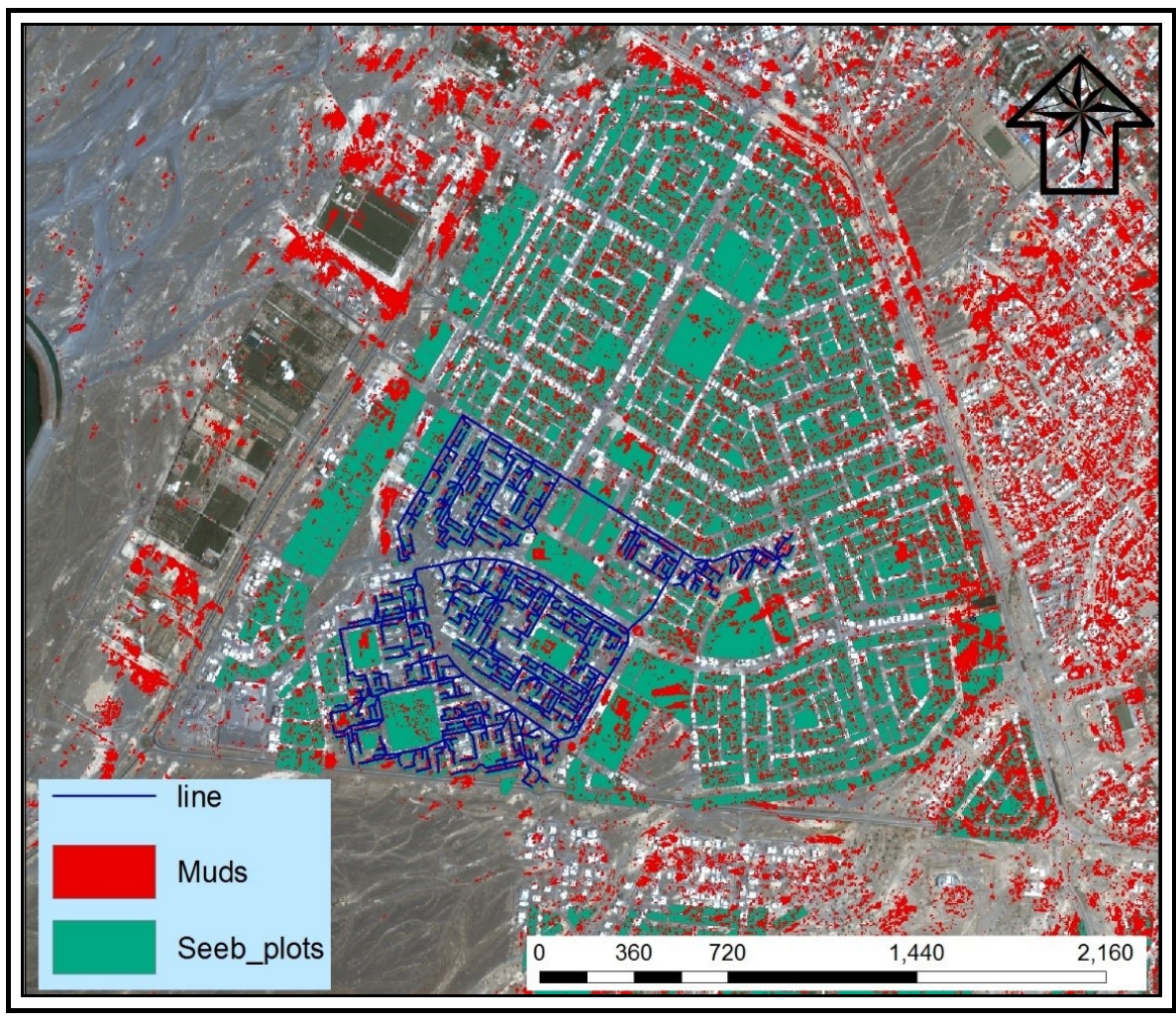

Figure 7. The extent of muds after Gonu tropical cyclone in the study area, Produced by Authors. 
It can be seen from Figure (7). The extent of muds (red colour) after Gonu tropical cyclone in the study area especially in the residential area between buildings. Mud covered about $2.56 \mathrm{KM}^{2}$ which represent $36.65 \%$ of the study Area. Mud can enter sewer lines from driveway or area drains. Mud will not break down into a liquid form like sewerage, this mud tends to accumulate and create a stoppage. This will require cleaning drains and perform maintenance after the cyclones which will require extra efforts, cost, and time. The extent of the wetland (yellow colour) can be observed clearly from Figure (8). The total area of the wetlands was $5.43 \mathrm{KM}^{2}$ which represent $77.45 \%$ of the study area.

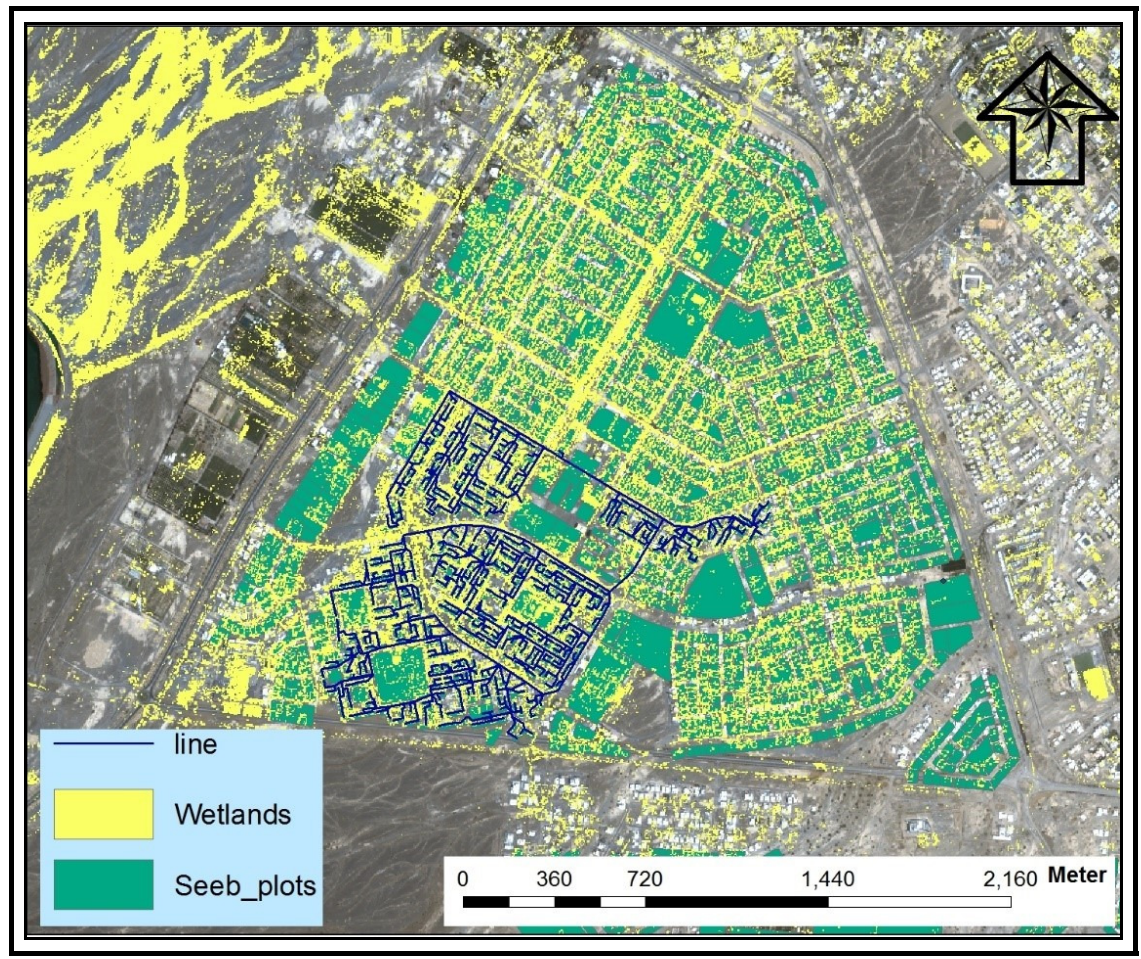

Figure 8. The extracted wetlands after Gonu tropical cyclone in the study area, Produced by Authors.

\section{4) Evaluating the Suitability Location of the Current Sewage Treatment Plant (STP)}

According to the Urban Planning Guide that has been prepared by the Supreme Committee for Town Planning in Oman, there are some criteria that should be met when thinking to build a Sewage Treatment Plant (STP), some of these criteria are: 
- $\quad$ STP must be away from Residential area.

- $\quad$ STP must be away from Water sources.

- $\quad$ STP must be away from areas that are subjected to flooding.

- $\quad$ STP must be near from roads.

Figure (9) illustrates the location of the current STP in AL Khoud area of study.

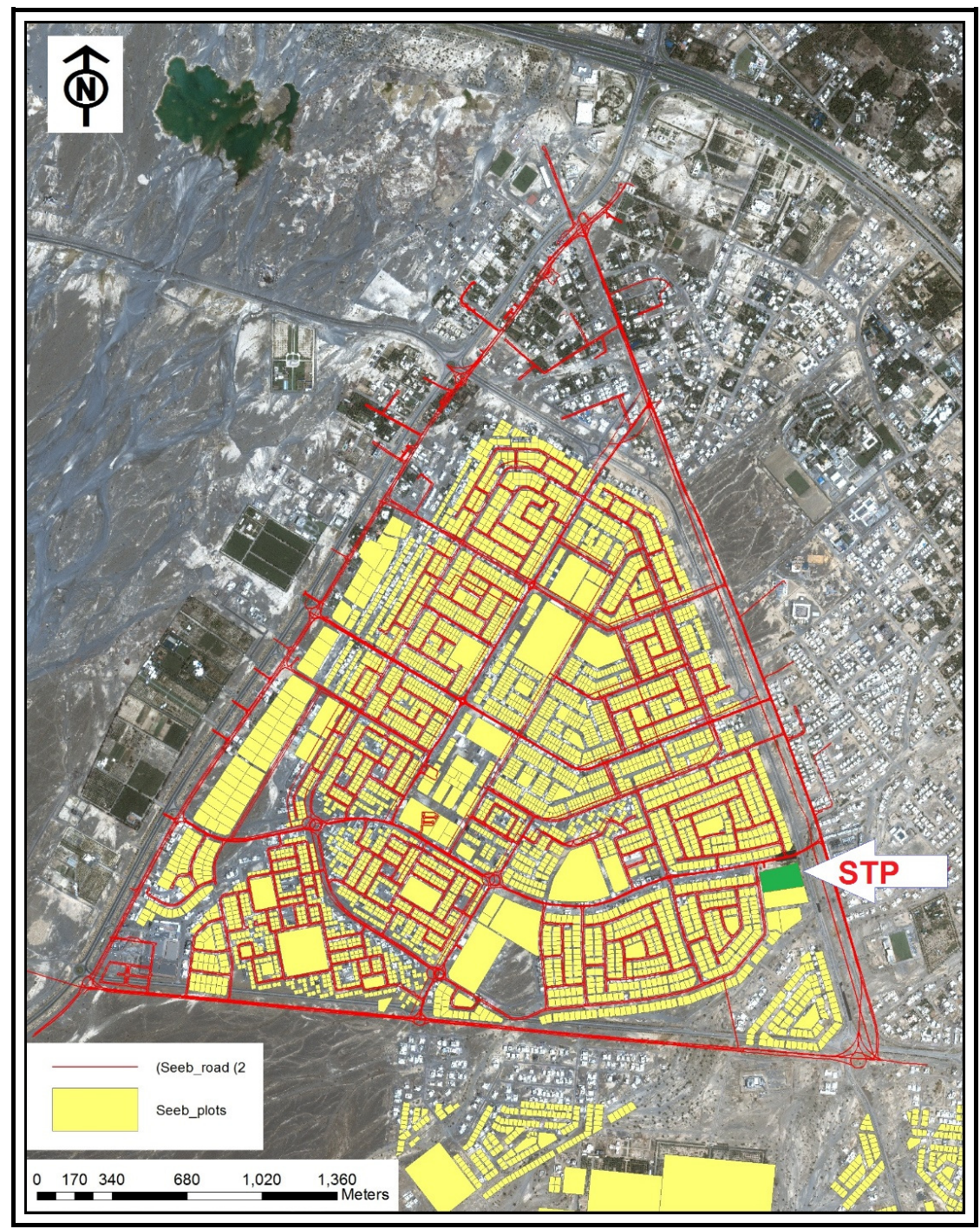

Figure 9. Location of the current STP in AL Khoud area of study, Produced by Authors. 
From this figure, it can be observed that the current location is not far away from the Residential area, but it is located in the area itself. This is the most important criteria that should be observed, therefore, it is recommended to search for another location which meet most of the required planning standards.

\section{Recommendations}

\section{1) Short Term Recommendations}

1. For the problem of sewage network pipes that pass through the buildings, this problem can be solved by passing the main line outside the buildings (black lines) including the main manholes (Figure 10).

2. As, the sewage network has been established more than 10 years ago, and due to the population complaints, therefore, it needs a lot of major maintenance operations.

3. The sewage network was designed with a small diameter pipes, as there were no expectation for the huge future population increase in the area of study. This problem can be solved by replacing the current pipes by wider pipes that can tolerate the increased pressure due to the population growth. In addition to that, it is imperative to select high quality materials in pipes manufacturing so that it can resist the moisture and pressure.

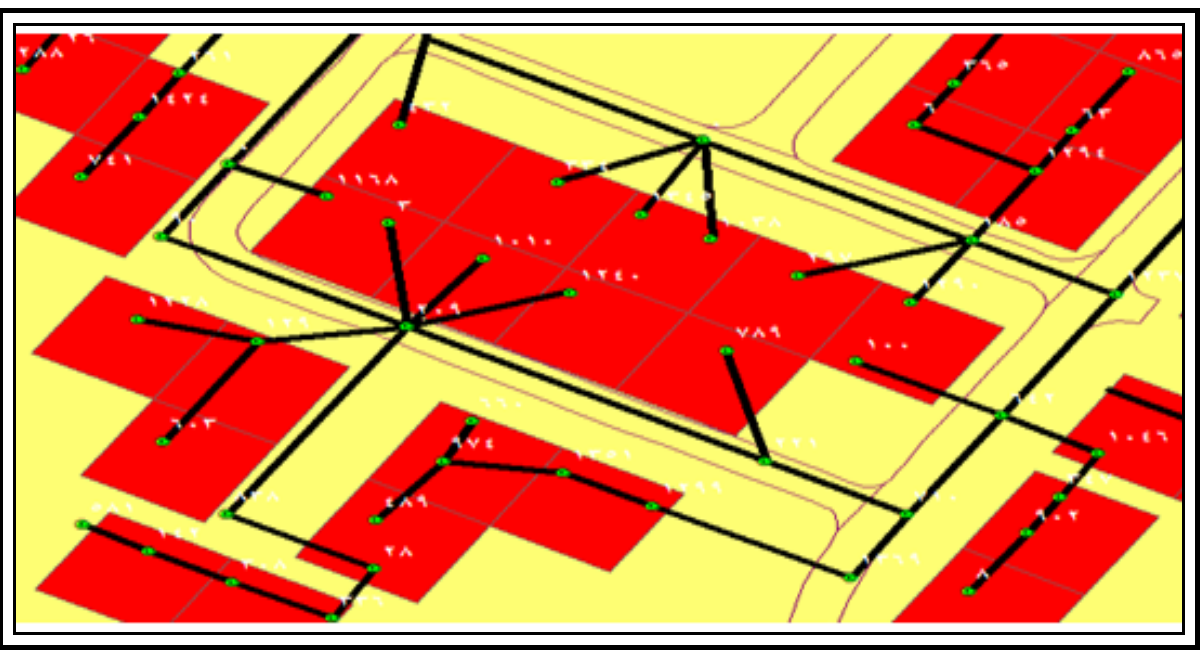

Figure 10. The suggested solution for the pipes problem, Produced by Authors. 


\section{2) Long Term Recommendations}

a. Finding best Location for future Sewage Treatment Plant (STP)

It was recommended before to search for another location which meet most of the required planning standards. As, there is no numeric values for Omani Urban Planning standards regarding the location of the Sewage Treatment Plant (STP), the following figures have been suggested for the best location criteria:

- $\quad$ STP must be away from Residential area by 100 meters

- $\quad$ STP must be away from Water sources by 250 meters

- $\quad$ STP must be away from areas that are subjected to flooding by 250 meters.

- $\quad$ STP must be near from roads by 50 meters.

Spatial Analysis using Buffering in ArcMap has been applied on the area of study using the following criteria:

- $\quad$ Built up Layer (buffered $100 \mathrm{~m}$ ).

- Wadi Layer (buffered $250 \mathrm{~m}$ ).

- Roads Layer (buffered distance $=50 \mathrm{~m}$ ).

Figure (11) shows the unsuitable locations for building a new STP. Figure (12) shows the map of the suitable locations for future STP.

\section{b. Defining the best size for future Sewage Treatment Plant (STP)}

It is important to define the best size for future Sewage Treatment Plant (STP) according to the population size in the future to sustain sewage service without any network problems. The Population size in the area of study was 1521 person in 2003, this figure become 3994 in 2010. The following equation is used to calculate the expected population in study area for the next years:

Where:

\section{$\log A+\{(\mathbf{N} X \log (\mathbf{1}+\mathbf{R})\} \quad$ (Peacock, 1940)}

$\mathrm{A}=$ Last census

$\mathrm{N}=$ Number of years

$\mathrm{R}=$ Annual increasing rate

The expected population in 2015 was 7960 and the forecasted size of population in 2020 is 15864 . Figures confirm that the population size is doubled nearly every 5 years and this should be considered when planning for any future infrastructure in this area especially sewage networks and sewage treatment plant. 


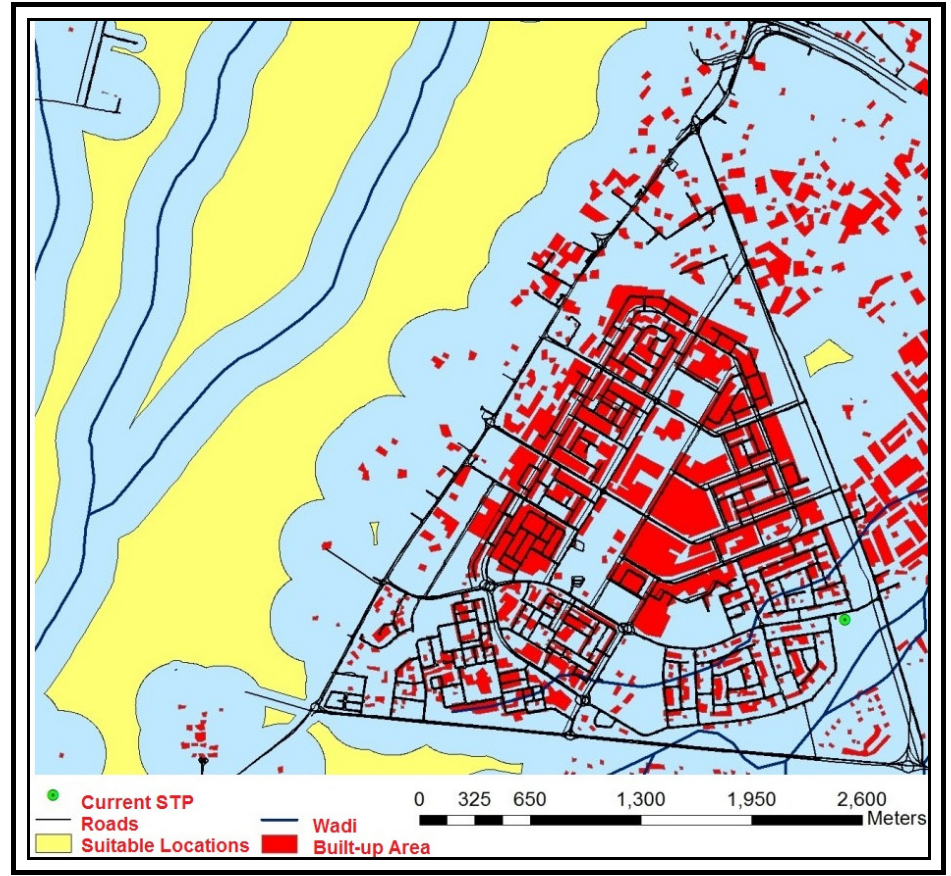

Figure 11. Suitability Locations for STP, Produced by Authors.

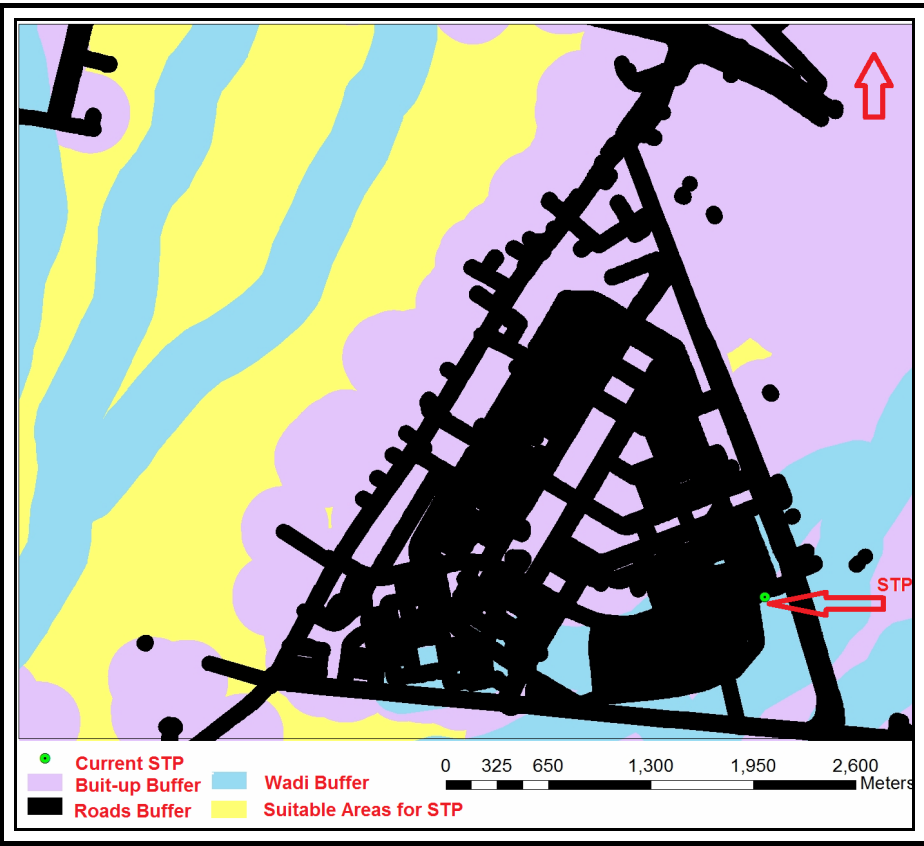

Figure 12. Buffering roads, wadis and built up area, Produced by Authors. -214- 
After calculation of population forecasting in the future, it is required to calculate the wastewater use in the study area. Oman Urban Planning Guide suggests the following figures of wastewater flows according to the income levels (Table 3).

Table 3. Standards of wastewater flows in Oman, Produced by Authors.

\begin{tabular}{|l|c|c|}
\hline & $\mathbf{1 9 9 9}$ & $\mathbf{2 0 0 3}$ \\
\hline $\begin{array}{l}\text { High Income } \\
\text { (Liter/person/day) }\end{array}$ & 200 & 240 \\
\hline $\begin{array}{l}\text { Average Income } \\
\text { (Liter/person/day) }\end{array}$ & 160 & 200 \\
\hline $\begin{array}{l}\text { Low Income } \\
\text { (Liter/person/day) }\end{array}$ & 80 & 120 \\
\hline
\end{tabular}

This study has adopted the high-income level which is 240 (Liter/ person/day), according to that:

The size of STP in $2015=240 * 7960=1910400$

STP size $=1910400 / 1000=1910.4$

Litres/Day

$=1910.4$ Kilo Litre Demand

Cubic Meter/Day

The size of STP in $2020=240 * 15864=3807360 \quad$ Litres/Day

STP size $=3807360 / 1000=3807.36 \quad$ Cubic Meter $/$ Day

$=3807.36 \quad$ Kilo Litre Demand

This figures may be used as a guidance for the decision makers to select the best option according to budget and planning standards.

\section{Conclusion}

This study proofed the importance of utilizing GIS in sewage networks analysis. Spatial Analysis has been applied in this study for defining the area which is served by the sewage network and the area which is not served by sewage network, and calculating percentage of each area. GIS has been used to calculate the capacity of the existing sewage network and the Sewage treatment plants in the study area. Spatial Analysis has been applied to define the impacts of Gono tropical Cyclone on the sewage network in the study area. GIS has been used to evaluate the suitability of the current location of the Sewage Treatment Plant (STP). GIS has been used to Search for the best location for Sewage Treatment Plant (STP) in the study area. Finally, GIS has been used for defining the best size for future Sewage Treatment Plant (STP). 


\section{References}

1. Alvarez-Vazquez, Martınez A, Rodriguez C, Vazquez-Mendez ME. (2002) Numerical optimization for the location of wastewater outfalls. Computational Optimization and Applications - Springer; 22(3): 399-417.

2. Atlas of Population (2012): Ministry of National Economy.

3. Azaz (2009): Capabilities of Using Remote Sensing and GIS for Tropical Cyclones Forecasting, Monitoring, and Damage Assessment, in Indian Ocean Tropical Cyclones and Climate Change book, pp 177-186

4. Civil Engineers PK (2017): Design of Sewer System, http://civilengineerspk.com/design-of-sewer-system/

5. Malczewski J. (2006): Ordered weighted averaging with fuzzy quantifiers: GISbased multicriteria evaluation for land-use suitability analysis, International Journal of Applied Earth Observations and Geoinformation

6. NASA, (2015), Volume, Editor: Nancy Hall, https://www.grc.nasa.gov/www/k12/airplane/volume.html\#

7. Peacock, George (1940): A treatise on algebra, New York, N.Y., Scripta mathematica, Yeshiva college

8. Urban Planning Guide (2008): Supreme Committee for Town Planning, Oman

9. Vesilind PA. (2003): Wastewater treatment plant design. Alexandria, VA: Water Environment Federation \& IWA Publishing. 